\title{
Chrysin induces autophagy through the inactivation of the ROS-mediated Akt/mTOR signaling pathway in endometrial cancer
}

\author{
$\mathrm{YU} \mathrm{HE}^{1 *}, \mathrm{YUCHUAN} \mathrm{SHI}^{1 *}, \mathrm{YANG} \mathrm{YANG}^{2}$, HUANHUAN HUANG $^{1}$, \\ YIFAN FENG ${ }^{1}$, YUNMENG WANG ${ }^{1}$, LEI ZHAN $^{1}$ and BING WEI ${ }^{1}$ \\ Departments of ${ }^{1}$ Gynecology and Obstetrics and ${ }^{2}$ Clinical Pharmacology, \\ The Second Affiliated Hospital of Anhui Medical University, Hefei, Anhui 230601, P.R. China
}

Received January 5, 2021; Accepted May 27, 2021

DOI: $10.3892 /$ ijmm.2021.5005

\begin{abstract}
Endometrial cancer (EC) is widely known as an aggressive malignancy. Due to the limited therapeutic options and poor prognosis of patients with advanced-stage EC, there is a need to identify effective alternative treatments. Chrysin is a naturally active flavonoid (5,7-dihydroxyflavone), which has been demonstrated to exert anticancer effects and may present a novel strategy for EC treatment. However, the role of chrysin in EC remains largely unclear. The aim of the present study was to examine the anticancer effects of chrysin on EC. The results revealed that, in addition to apoptosis, chrysin increased the LC3II expression levels and markedly accelerated the autophagic flux, suggesting that chrysin induced both the autophagy and apoptosis of EC cells. Furthermore, the inhibition of autophagy by chloroquine enhanced the inhibitory effect on cell proliferation and the promotion of the chrysin-induced apoptosis of EC cells, indicating that chrysin-induced autophagy was a cytoprotective mechanism. Additionally, chrysin led to the production of intracellular reactive oxygen species (ROS). $N$-acetylcysteine (NAC) pretreatment significantly inhibited chrysin-induced autophagy, suggesting that ROS activated autophagy induced by chrysin in EC cells. Furthermore, the phosphorylated (p-) Akt and p-mTOR levels were significantly decreased in a concentration-dependent manner following treatment with chrysin, while NAC blocked these effects. Taken together, these findings demonstrated that chrysin-induced autophagy
\end{abstract}

Correspondence to: Dr Bing Wei, Department of Gynecology and Obstetrics, The Second Affiliated Hospital of Anhui Medical University, 678 Furong Road, Hefei, Anhui 230601, P.R. China E-mail:m1351565@163.com

*Contributed equally

Key words: endometrial cancer, chrysin, autophagy, apoptosis, reactive oxygen species, Akt/mTOR via the inactivation of the ROS-mediated Akt/mTOR signaling pathway in EC cells.

\section{Introduction}

Endometrial cancer (EC) is considered one of the most common gynecological malignancies in industrialized countries (1). Primarily due to relevant risk factors, including obesity, diabetes and aging, among others, its incidence is gradually increasing (2,3). Recurrent or advanced EC responds poorly to treatment. Few therapeutic options are available for such patients, who therefore have low survival rates and a poor prognosis (4). The 5-year survival rate for patients with stage IV disease is limited only at 0-10\% (5). Accordingly, EC is increasingly recognized as a serious health and epidemiological concern. Thus, novel therapeutic approaches that can effectively reduce morbidity and mortality in EC are urgently required.

In recent years, natural compounds for cancer prevention and treatment have gained attention due to their anticancer activity and safety, and are a rich source of phytochemicals. They are an integral part of the human diet $(6,7)$. The use of natural compounds combined with targeted drugs may provide new perspectives for the development of anticancer drugs. Chrysin (5,7-dihydroxyflavone; chemical structure shown in Fig. 1A) is a natural dietary flavonoid, commonly present in various plant extracts, including honey and propolis. It has a notable medicinal functions and economic value (8). Additionally, chrysin has diverse biological properties, specifically including anticancer, antioxidant, anti-inflammatory, antibacterial, anti-diabetic and anti-allergenic effects $(9,10)$. Recently, several studies have reported that chrysin exerts its cancer-suppressive effects on breast, lung, cervical and bladder cancer cells through regulating multiple cell signaling pathways selectively (11-15). However, the anti-EC possible mechanisms of chrysin have not yet been fully elucidated.

Cancer cell death is often caused by apoptosis, which is considered to be the principal anticancer mechanism (16). However, it has been documented that autophagy and apoptosis are intertwined processes (17). Autophagy is the process of engulfing and degrading cytosolic proteins and damaged 
organelles (18). It has been reported that the inhibition of autophagy increases the anticancer efficiency by inducing the apoptotic process (19). In addition, reactive oxygen species (ROS) have been found to be the associated factors in the anticancer effects of chrysin-induced autophagy. For example, Lin et al (20) indicated that chrysin induced ROS production and then autophagy, resulting in the attenuation of the viability of human colorectal cancer cells. This suggests that there may be a link among anticancer drugs, such as chrysin, ROS levels and autophagy pathways in EC. However, to date, at least to the best of our knowledge, there are no reports on the pharmacological mechanisms of chrysin in EC, particularly concerning its role in the regulation of cell ROS levels and autophagy pathways, which remains unclear.

The present study thus aimed to investigate the molecular mechanisms of the anticancer role of chrysin and focused on how the compound regulates the autophagy pathway in EC cells.

\section{Materials and methods}

Reagents and antibodies. Chrysin and LY294002 were purchased from MedChemExpress. $N$-acetylcysteine (NAC) and chloroquine (CQ) were obtained from Sigma-Aldrich (Sigma-Aldrich; Merck KGaA). The cells were pretreated

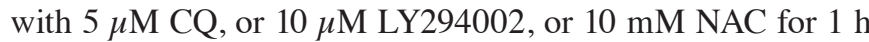
and were then treated with chrysin for additional 24 or $48 \mathrm{~h}$. The antibodies used for western blotting included monoclonal anti-LC3 (dilution 1:1,000; cat. no. ab192890; Abcam), monoclonal anti-sequestosome-1/p62 (dilution 1:1,000; cat. no. ab207305; Abcam), monoclonal anti-autophagy-related gene 5 (ATG5; dilution 1:1,000, cat. no. ab108327; Abcam), polyclonal anti-Beclin 1 (dilution 1:1,000; cat. no. AF5128; Affinity Biosciences), polyclonal anti-Bcl-2 (dilution 1:1,000; cat. no. AF6139; Affinity Biosciences), polyclonal anti-Bax (dilution 1:1,000; cat. no. AF0120; Affinity Biosciences), monoclonal anti-Akt (dilution 1:1,000; cat. no. 4691; Cell Signaling Technology, Inc.), monoclonal anti-phosphorylated (p)-Akt (Ser473; dilution 1:1,000; cat. no. 4060; Cell Signaling Technology, Inc.), monoclonal anti-mTOR (dilution 1:1,000; cat. no. 2983; Cell Signaling Technology, Inc.), monoclonal anti-p-Mtor (Ser2448; dilution 1:1,000; cat. no. 5536; Cell Signaling Technology, Inc.) and polyclonal anti-GAPDH (dilution 1:10,000; cat. no. AF7021; Affinity Biosciences). Horseradish peroxidase-conjugated goat anti-rabbit IgG (dilution 1:10,000; cat. no. ZB-2301) and goat anti-mouse IgG (dilution 1:10,000; cat. no.ZB-2305) secondary antibodies were purchased from Beijing Zhongshan Jinqiao Biotechnology, Co., Ltd.

Cell lines and cell culture. The human endometrioid adenocarcinoma cell line, HEC-1A (cat. no. HTB-112), was purchased from the American Type Culture Collection (ATCC) and the endometrioid adenocarcinoma cell line, Ishikawa (cat. no. 99040201), was purchased from the European Collection of Authenticated Cell Cultures (ECACC). Cells were maintained in high-glucose DMEM (Gibco; Thermo Fisher Scientific, Inc.) supplemented with $10 \%$ v/v FBS (Gibco; Thermo Fisher Scientific, Inc.) and penicillin/streptomycin $(100 \mathrm{U} / \mathrm{ml}$ penicillin and $100 \mu \mathrm{g} / \mathrm{ml}$ streptomycin;
Gibco; Thermo Fisher Scientific, Inc.) at $37^{\circ} \mathrm{C}$ in a $95 \% \mathrm{O}_{2}$ and $5 \% \mathrm{CO}_{2}$ atmosphere in a humidified incubator.

Cell viability assay. The Cell Counting Kit-8 (CCK-8; Biosharp Life Sciences) was used to analyze the viability of the HEC-1A and Ishikawa cells following treatment with chrysin. Briefly, $5 \times 10^{3}$ cells in $100 \mu \mathrm{l}$ medium were plated into each well of a 96-well plate until they became adherent. In experiments evaluating the effect of chrysin alone, cells were treated with chrysin $(0,10,20,40$ and $80 \mu \mathrm{M})$ for 24,48 or $72 \mathrm{~h}$. In the experiments that evaluated the combined effect of chrysin and CQ, cells were pretreated with $5 \mu \mathrm{M}$ CQ for $1 \mathrm{~h}$ prior to exposure to $40 \mu \mathrm{M}$ chrysin, and the cells were then further incubated for $48 \mathrm{~h}$ at $37^{\circ} \mathrm{C}$. Subsequently, $10 \% \mathrm{CCK}-8$ solution (the ratio of volume of medium and CCK-8 was 9:1) was added to the culture medium. Following further incubation for $1 \mathrm{~h}$ at $37^{\circ} \mathrm{C}$ in the dark, a Varioskan LUX microplate reader (Thermo Fisher Scientific, Inc.) was used to measure the absorbance at $450 \mathrm{~nm}$ in each well.

Colony formation assay. HEC-1A and Ishikawa cells were inoculated into 6-well plates at a low cell density (1,000 cells per well) and incubated at $37^{\circ} \mathrm{C}$ overnight. The cells were the exposed to $40 \mu \mathrm{M}$ chrysin and cultured for $\sim 1$ week. The medium was replaced every 3 days, in order to maintain stable chrysin concentration levels. The plates were periodically observed until distinct colonies were formed and then fixed with $4 \%$ paraformaldehyde. After staining with $0.1 \%$ crystal violet solution (Beyotime Institute of Biotechnology) for $15 \mathrm{~min}$ at room temperature, the colonies ( $>50$ cells per colony) were counted with ImageJ software (version 1.38; National Institutes of Health).

Flow cytometric analysis. Apoptotic cells were detected by flow cytometry and quantified according to the percentage of apoptotic cells in each group. Briefly, HEC-1A and Ishikawa cells that had been treated with the indicated concentrations of chrysin with or without $5 \mu \mathrm{M}$ CQ were digested with trypsin without EDTA and harvested. Subsequently, the cells were resuspended in $100 \mu \mathrm{l}$ binding buffer, and incubated with $5 \mu \mathrm{l}$ Annexin V-FITC and $10 \mu \mathrm{l}$ propidium iodide (PI) for $15 \mathrm{~min}$ at room temperature in the dark. The apoptotic ratio was measured using a Navios flow cytometer (Beckman Coulter, Inc.). The upper and lower right quadrants on the dot-plot graphs represented late and early apoptotic cells, respectively.

Transmission electron microscopy (TEM) examination. To observe the cell morphological changes of autophagosomes and autolysosomes, TEM was performed. Briefly, HEC-1A and Ishikawa cells, following exposure to $40 \mu \mathrm{M}$ chrysin for $48 \mathrm{~h}$, were fixed with $2.5 \%$ glutaraldehyde at $4^{\circ} \mathrm{C}$ overnight, and then post-fixed with $1 \%$ osmium tetroxide $\left(\mathrm{OsO}_{4}\right)$ for $1 \mathrm{~h}$ followed by incubation with $2 \%$ uranyl acetate at room temperature for a further $1 \mathrm{~h}$. After washing with phosphate-buffered saline (PBS; Gibco; Thermo Fisher Scientific, Inc.), the cells were dehydrated in an ethanol series, infiltrated with propylene oxide and finally embedded in epoxy resin. Ultrathin sections (70 $\mathrm{nm}$ ) were prepared, stained with uranyl acetate and lead citrate, and then examined in a JEM-1400 TEM system (JEOL, Ltd.). 
A<smiles>O=c1cc(-c2ccccc2)oc2cc(O)cc(O)c12</smiles>

B

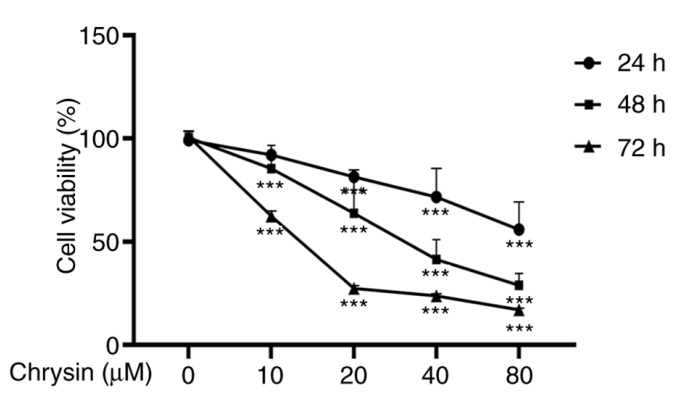

C

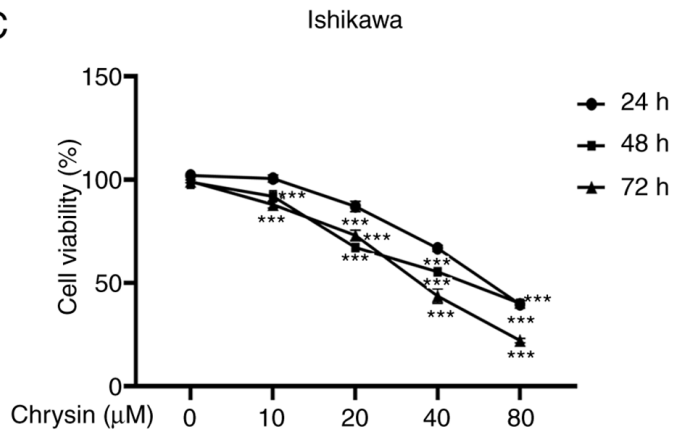

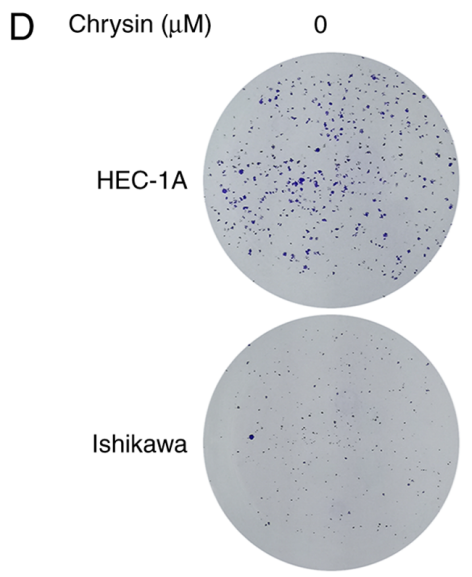

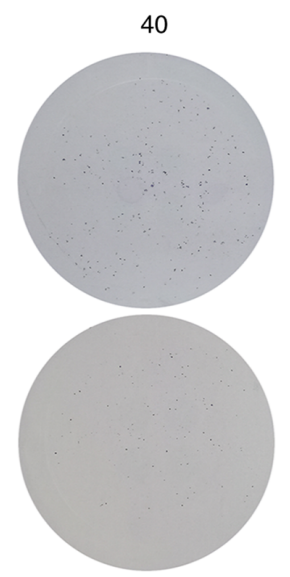

Figure 1. Continued.

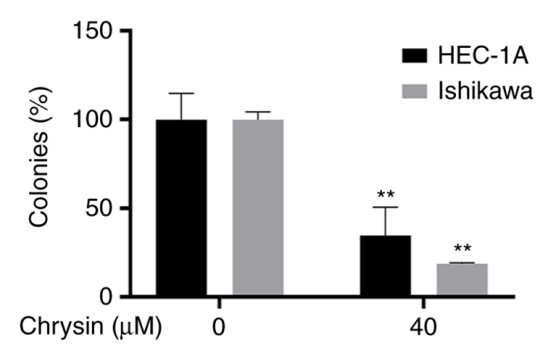

Western blotting. The cells were lysed with RIPA lysis buffer (Beyotime Institute of Biotechnology), and the supernatant was collected by centrifugation at $13,000 \mathrm{x}$ g for $30 \mathrm{~min}$ at $4^{\circ} \mathrm{C}$ in order to extract total cellular protein. After quantifying the protein concentration in the supernatant using a BCA protein assay kit (Beyotime Institute of Biotechnology), total protein was mixed by loading buffer and boiled at $100^{\circ} \mathrm{C}$ for $5 \mathrm{~min}$. The denatured cell proteins $(10-20 \mu \mathrm{g})$ were separated on $6-15 \%$ SDS-PAGE according to the molecular weight of the target proteins, and subsequently transferred onto polyvinylidene difluoride membranes. The membranes were then blocked for $2 \mathrm{~h}$ at room temperature in 5\% skimmed milk, and then incubated with the aforementioned diluted primary antibodies at $4^{\circ} \mathrm{C}$ overnight, following by incubation with the aforementioned secondary antibodies for $1 \mathrm{~h}$ at room temperature. The protein bands were visualized with an enhanced chemiluminescent reagent (Thermo Fisher Scientific, Inc.), and analyzed using ImageJ version 1.38 (National Institutes of Health).

Immunofluorescence assay. Following treatment with $40 \mu \mathrm{M}$ chrysin for 48 h, HEC-1A and Ishikawa cells were fixed with $4 \%$ paraformaldehyde for $15 \mathrm{~min}$. Following permeabilization with $0.5 \%(\mathrm{v} / \mathrm{v})$ Triton $\mathrm{X}-100$ for $15 \mathrm{~min}$ at room temperature, the cells were blocked with $5 \%$ bovine serum albumin (Beyotime Institute of Biotechnology) for $30 \mathrm{~min}$ and incubated with anti-LC3 antibody (dilution 1:200; cat. no. ab192890; Abcam) overnight at $4^{\circ} \mathrm{C}$. Finally, the cells were incubated with the FITC-labeled goat anti-rabbit $\operatorname{IgG}(\mathrm{H}+\mathrm{L})$ secondary antibody (dilution 1:400; cat. no. A0562; Beyotime Institute of Biotechnology) for $1 \mathrm{~h}$ at room temperature, and the cell nuclei finally were stained with DAPI for $10 \mathrm{~min}$ in the dark. All samples were imaged using an Axio Scope A1 fluorescence microscope (Zeiss $\mathrm{GmbH})$.

Intracellular reactive oxygen species (ROS) analysis. Intracellular ROS levels were determined using a ROS assay kit (Beyotime Institute of Biotechnology); 2',7'-dichlorofluorescein diacetate (DCFH-DA), a ROS-sensitive fluorescent dye, was used as the ROS detection probe. DCFH-DA was deacetylated to non-fluorescent DCFH, and ROS then oxidized DCFH to produce fluorescent DCF. The fluorescence intensity was proportional to the oxidant production levels. HEC-1A and Ishikawa cells were treated with $5 \mu \mathrm{M}$ CQ or $10 \mathrm{mM}$ NAC for $1 \mathrm{~h}$ prior to treatment with $40 \mu \mathrm{M}$ chrysin for $48 \mathrm{~h}$. Processed 


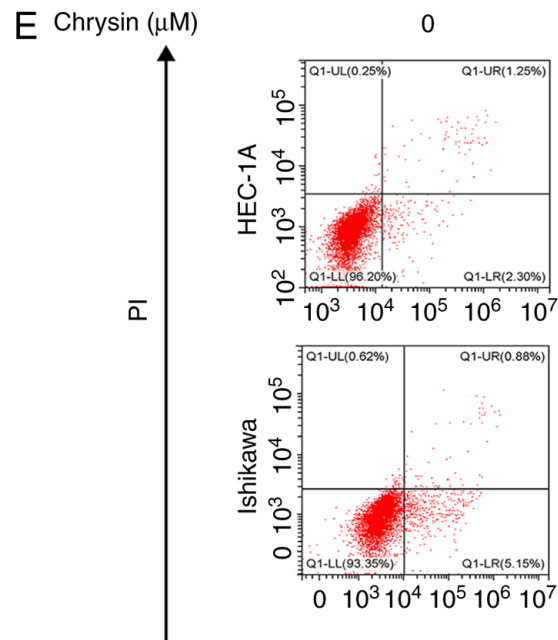

20
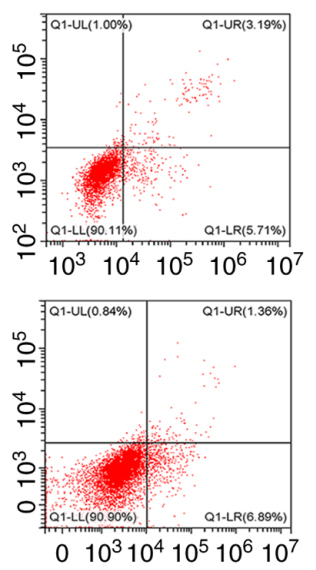

40
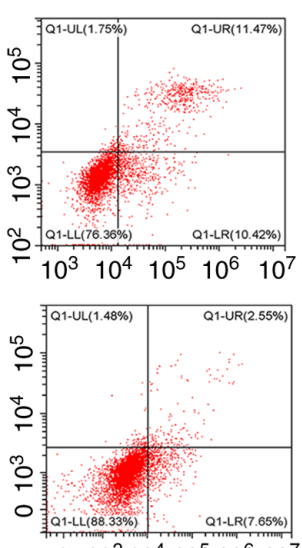

$010^{3} 10^{4} 10^{5} 10^{6} 10^{7}$
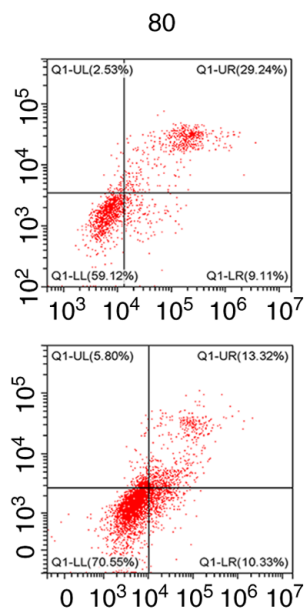

Annexin V-FITC

HEC-1A

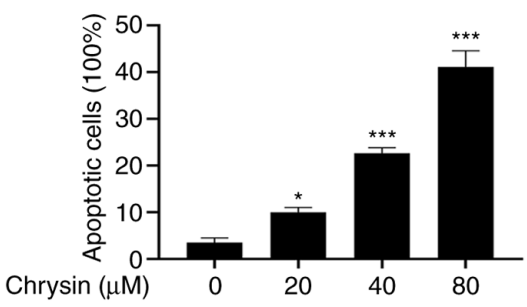

Ishikawa

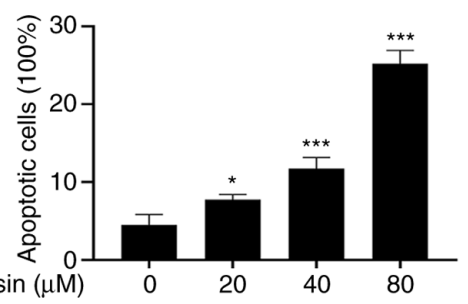

$\mathrm{F}$

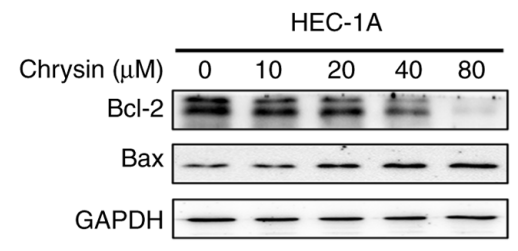

G

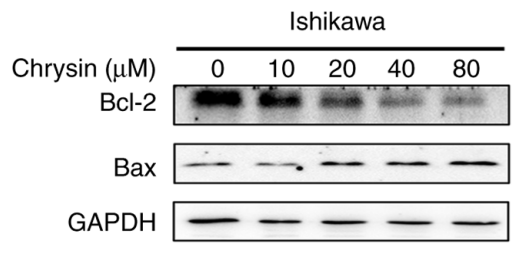

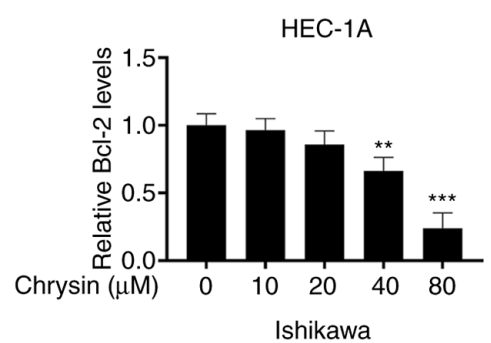

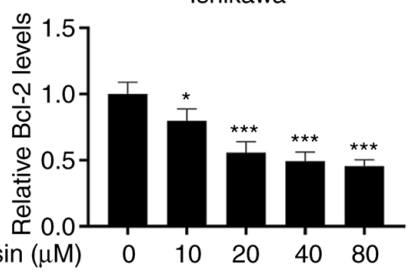

HEC-1A
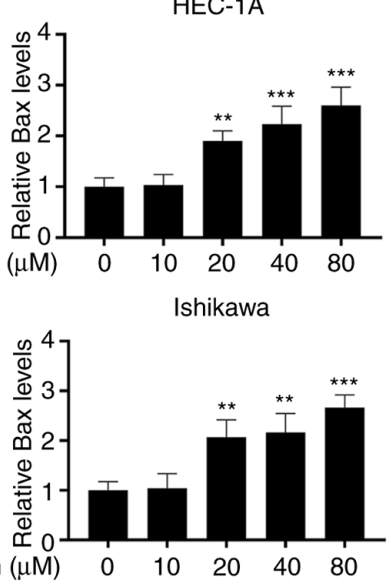

Figure 1. Chrysin inhibits the proliferation and induces the apoptosis of endometrial cancer cells. (A) Chemical structure of chrysin. (B and C) HEC-1A and Ishikawa cells were treated with chrysin $(0,10,20,40$ and $80 \mu \mathrm{M})$, and Cell Counting Kit- 8 solution was added at 24,48 and $72 \mathrm{~h}$. (D) Following $40 \mu \mathrm{M}$ chrysin treatment for $48 \mathrm{~h}$ in HEC-1A and Ishikawa cells, colony formation assay was performed. (E) Following treatment with chrysin $(0,20,40$ and $80 \mu \mathrm{M})$ for $48 \mathrm{~h}$, cell apoptosis was analyzed by flow cytometry using Annexin V-fluorescein isothiocyanate and $10 \mu 1$ propidium iodide staining in HEC-1A and Ishikawa cells. (F and G) HEC-1A and Ishikawa cells were exposed to chrysin $(0,10,20,40$ and $80 \mu \mathrm{M}$ ) for $48 \mathrm{~h}$, and the Bcl-2 and Bax levels were confirmed by western blot analysis. Data are expressed as the mean \pm standard deviation $(n=3) .{ }^{*} \mathrm{P}<0.05,{ }^{* *} \mathrm{P}<0.01,{ }^{* * * *} \mathrm{P}<0.001$ vs. control group.

cells were incubated with $10 \mu \mathrm{M}$ DCFH-DA diluted for $30 \mathrm{~min}$ at $37^{\circ} \mathrm{C}$ in the dark. The cells were then washed three times with serum-free DMEM to fully remove the probe. The levels of ROS, represented by the green fluorescence signal, were photographed with the use of a DP80 fluorescence microscope (Olympus Corporation).

Small interfering RNAs (siRNAs/si) and transfection. The target siRNA sequence was as follows: siATG5, 5'-GCA ACUCUGGAUGG-3'; and negative control siRNA, 5'-UUC UCCGAACGUGUCACGUTT-3'. All siRNAs were designed and synthesized by Shanghai GenePharma Co., Ltd. Prior to transfection, HEC-1A and Ishikawa cells were seeded into 6-well plates and cultured to $60-70 \%$ confluence. Cells were transfected with $50 \mathrm{nM}$ siRNA using $4 \mu$ jetPRIME $^{\circledR}$ Transfection Reagent (Polyplus-transfection ${ }^{\circledR}$ SA) in $200 \mu 1$ jetPRIME $^{\circledR}$ buffer. These mixtures were incubated for $15 \mathrm{~min}$ at room temperature and added to $2 \mathrm{ml}$ fresh medium per well of a 6-well plate. The cells were cultured for $24 \mathrm{~h}$, and then treated with $0-80 \mu \mathrm{M}$ chrysin for 24 or $48 \mathrm{~h}$.

Statistical analysis. Data are represented as the mean \pm standard deviation. The experiments were performed $\geq 3$ times. One-way ANOVA was used to compare the experimental groups to the 
control values, whereas comparisons between multiple groups were performed using Tukey's multiple comparison test. Statistical analysis was performed with GraphPad Prism 8.0 software (GraphPad Software, Inc.). $\mathrm{P}<0.05$ was considered to indicate a statistically significant difference.

\section{Results}

Chrysin inhibits the proliferation and induces the apoptosis of EC cells. CCK-8 assay revealed that chrysin exerted an inhibitory effect on the proliferation of HEC-1A and Ishikawa cells, in a concentration- and time-dependent manner (Fig. 1B and C). In addition, the colony formation activity of the HEC-1A and Ishikawa cells was significantly inhibited by chrysin (Fig. 1D). These results confirmed that chrysin inhibited the proliferation of EC cells.

To investigate whether chrysin induces the apoptosis of EC cells, cell apoptosis was examined by flow cytometry after double staining with Annexin V-FITC and PI. As shown in Fig. 1E, chrysin notably increased the proportion of apoptotic cells. Bax is a pro-apoptotic protein that leads to cell death, whereas Bcl-2 is an anti-apoptotic protein that promotes cell survival (21). Western blotting revealed that the treatment of HEC-1A and Ishikawa cells with chrysin for $48 \mathrm{~h}$ increased the level of Bax and decreased the expression of $\mathrm{Bcl}-2$ (Fig. 1F and G). These results demonstrated that chrysin induced the apoptosis of EC cells.

Chrysin initiates the autophagy of EC cells. As shown in Fig. 2A, TEM images indicated autophagosomes and autophagolysosomes in the chrysin group, which are characteristics of autophagic cells. In cells treated with $5 \mu \mathrm{M}$ CQ for $1 \mathrm{~h}$, prior to the application of $40 \mu \mathrm{M}$ chrysin for $48 \mathrm{~h}$, the aforementioned effects intensified. Immunofluorescence assay was used to detect the distribution of endogenous LC3 in HEC-1A and Ishikawa cells. In chrysin-treated cells, the intracellular localization of LC3 and abundant LC3 puncta were detected, while the control cells did not exhibit any noticeable fluorescence intensity (Fig. 2B and C). The results of western blot analysis revealed that, with an increased concentration of chrysin, the level of LC3II and Beclin 1 increased, which was accompanied by a decrease in p62 expression (Fig. 3A and B).

ATG5 participates in the vesicle elongation step of autophagy and plays critical roles in the process of autophagy (22). The present study demonstrated that the knockdown of ATG5 by siRNA reduced the chrysin-induced LC3II accumulation in HEC-1A and Ishikawa cells (Fig. 3C and D). Furthermore, the LC3II levels were markedly increased in the HEC-1A and Ishikawa cells pretreated with CQ, in comparison with the group treated with chrysin alone (Fig. 3E and F), thus confirming that chrysin promoted the autophagic flux. These results revealed that chrysin induced autophagy and increased the autophagic flux in EC cells.

The role of autophagy in chrysin-induced cell apoptosis was also assessed. The inhibition of autophagy by CQ significantly enhanced the cytotoxicity of chrysin to EC cells, which was demonstrated via the inhibition of proliferation (Fig. 4A-C) and the induction of apoptosis (Fig. 4D-F). Autophagy inhibition by CQ potentiated the chrysin-induced inhibition of cell proliferation and promoted the chrysin-induced apoptosis of
A

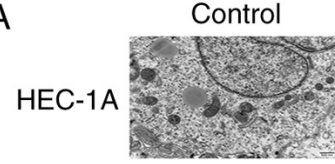

Ishikawa
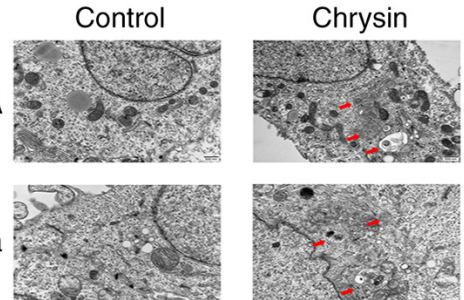

Chrysin $+\mathrm{CQ}$
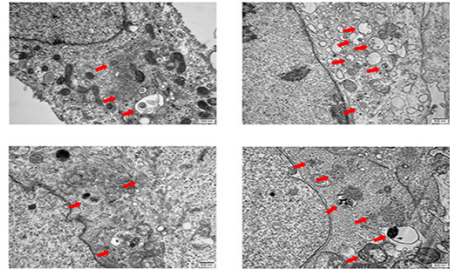

B

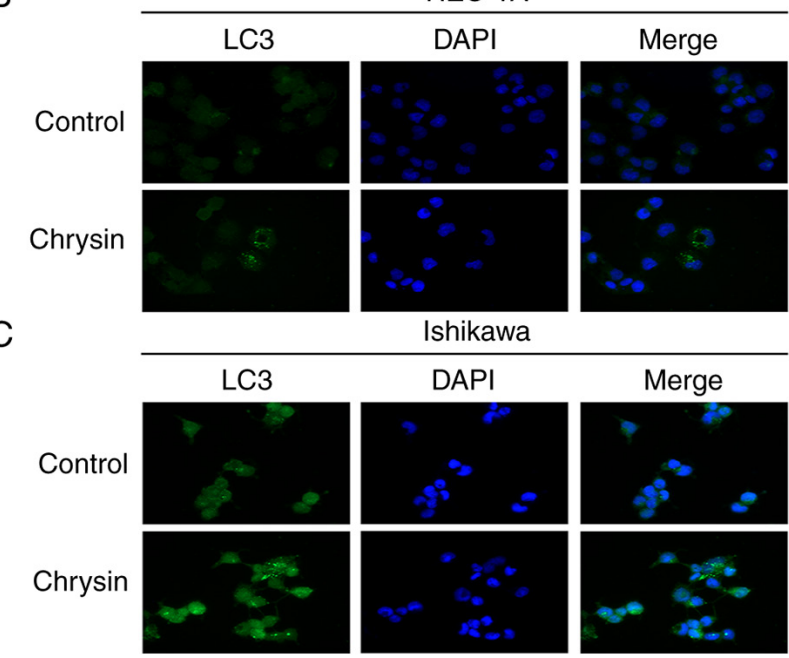

Figure 2. Chrysin stimulates autophagy in endometrial cancer cells. (A) HEC-1A and Ishikawa cells were untreated or treated with $5 \mu \mathrm{M} \mathrm{CQ}$ for $1 \mathrm{~h}$, followed by chrysin treatment at $40 \mu \mathrm{M}$ for $48 \mathrm{~h}$ and analyzed by transmission electron microscopy. Red arrows represent autophagosomes or autophagolysosomes. (B and C) HEC-1 A and Ishikawa cells were exposed to $40 \mu \mathrm{M}$ chrysin for $48 \mathrm{~h}$, and sections were stained for light chain 3 (green) and DAPI (blue), and measured using fluorescence microscopy (magnification, $\mathrm{x} 400)$. CQ, chloroquinone.

EC cells. Thus, chrysin induced cytoprotective autophagy in EC cells.

Chrysin induces autophagy via ROS in EC cells. The association between ROS and autophagy is complex. To clarify whether autophagy induced by chrysin in EC cells is regulated by ROS or not, HEC-1A and Ishikawa cells were treated with chrysin for $48 \mathrm{~h}$, and the level of ROS in cells was detected by DCF fluorescence intensity. Fluorescence microscopy demonstrated that chrysin-induced intracellular ROS accumulation was markedly increased, which was clearly inhibited by the ROS scavenger, NAC (Fig. 5A). ROS levels were increased to a greater extent in cells treated with a combination of chrysin and $\mathrm{CQ}$, as compared with that of cells treated with chrysin alone (Fig. 5B). Notably, NAC pretreatment inhibited the increase in the LC3II level induced by chrysin (Fig. 5C and D). Collectively, it was revealed that chrysin induces cellular ROS accumulation, which may be one of the reasons for autophagy induced by chrysin in EC cells.

ROS-mediated inactivation of the Akt/mTOR signaling pathway is involved in chrysin-induced autophagy in EC cells. To further investigate the potential mechanisms of autophagy induced by chrysin, the effect of chrysin on the expression of $\mathrm{Akt} / \mathrm{mTOR}$ in autophagy-related signaling pathways in EC was analyzed in the present study (23). The increase in chrysin 
A

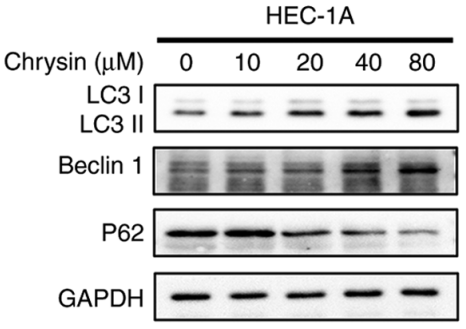

HEC-1A

HEC-1A

HEC-1A
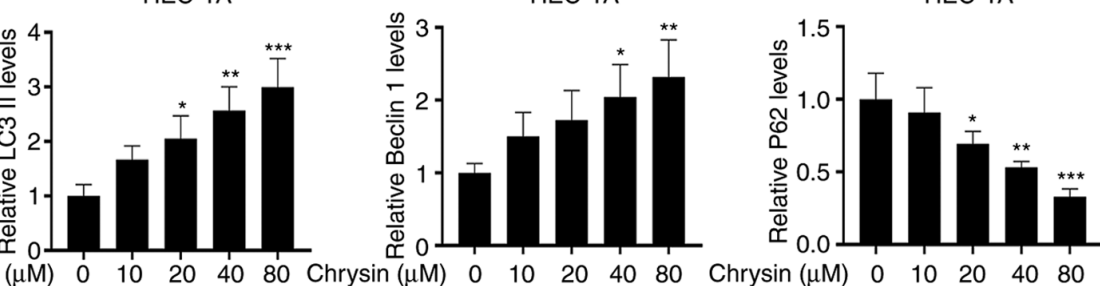

B

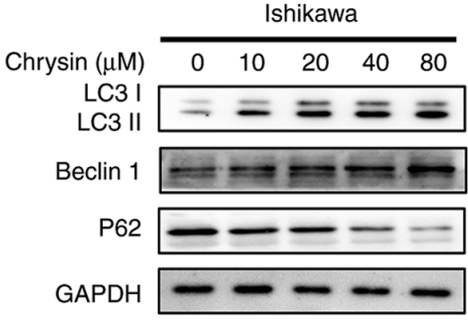

Ishikawa

Ishikawa

Ishikawa

C
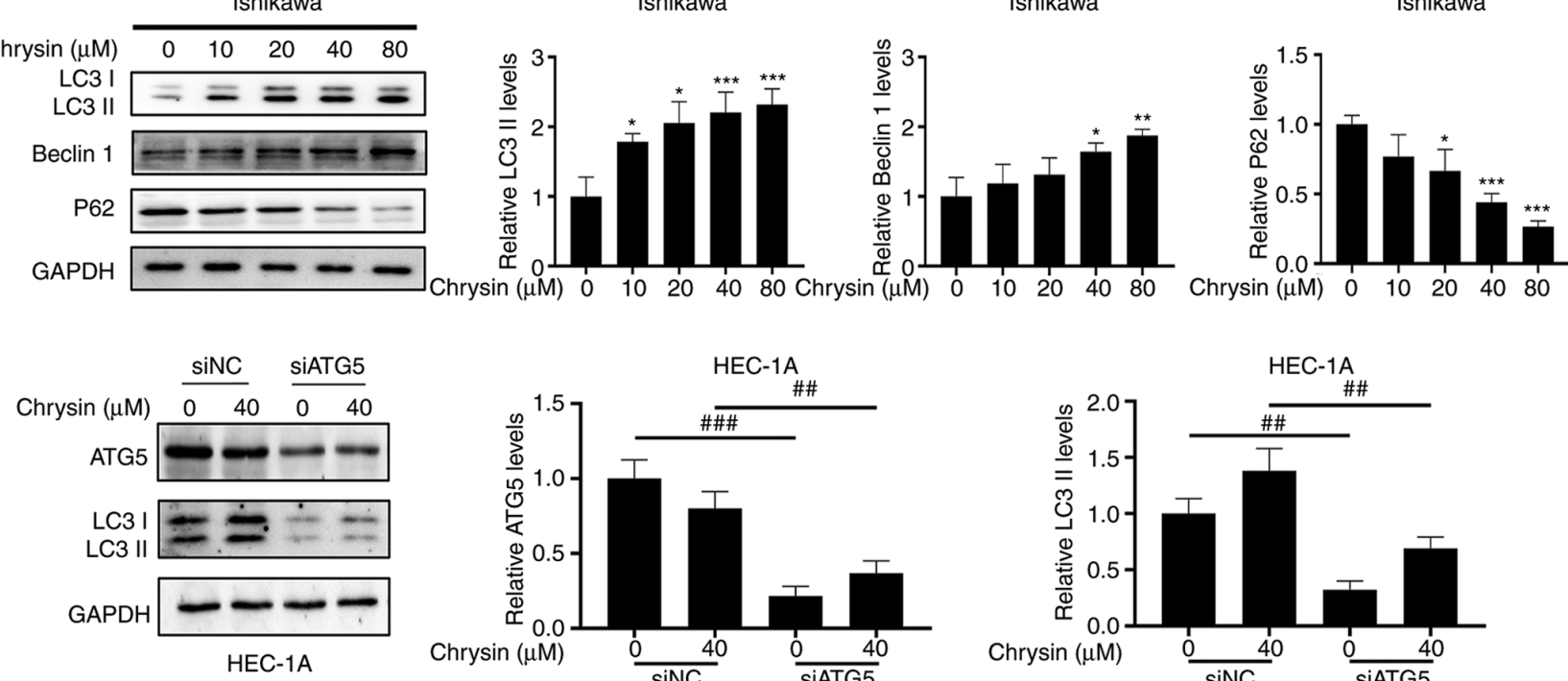

Chrysin $(\mu \mathrm{M}) \quad 0 \quad 10 \quad 20 \quad 40 \quad 80$

D
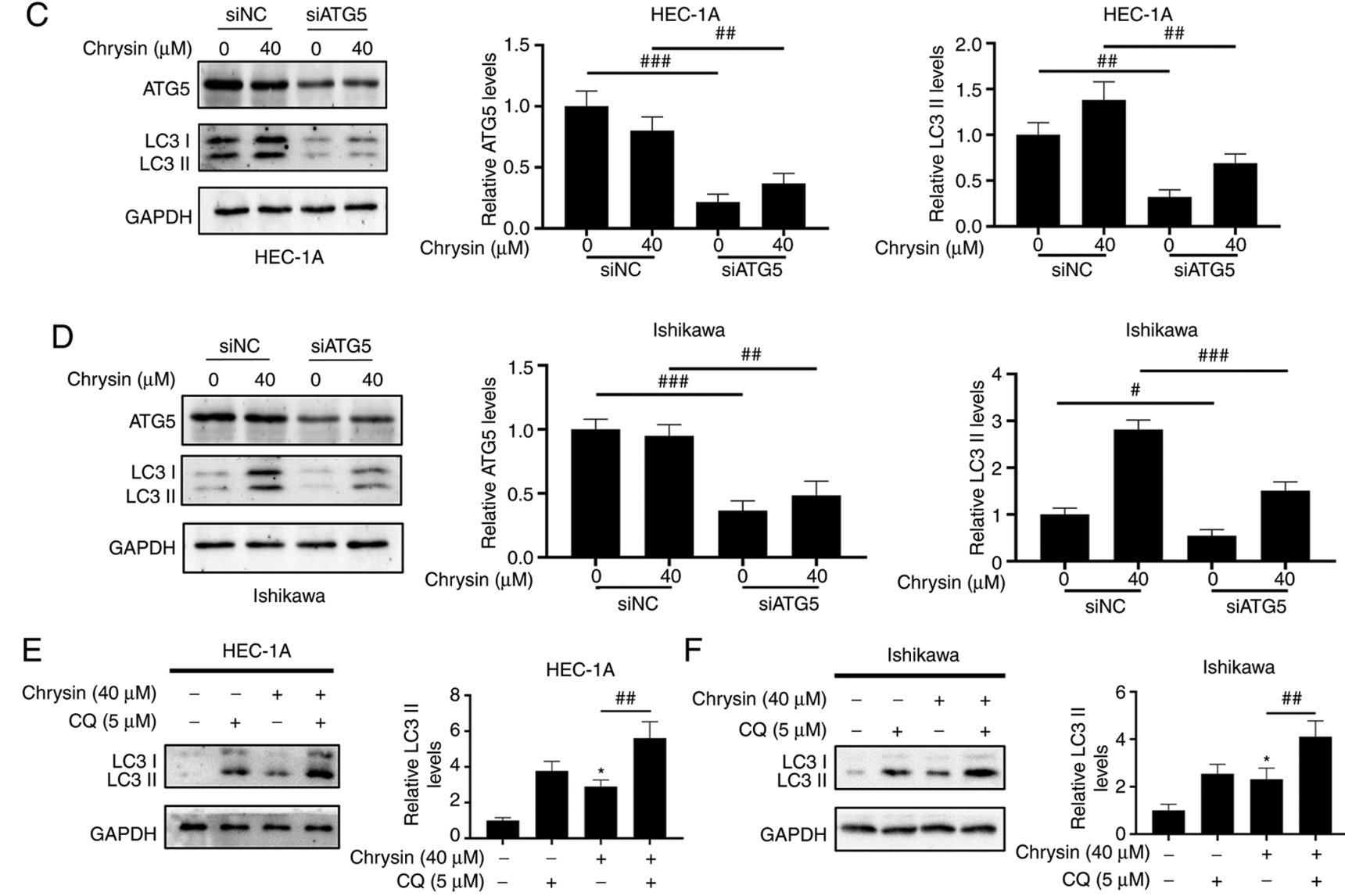

$\mathrm{F}$

Ishikawa
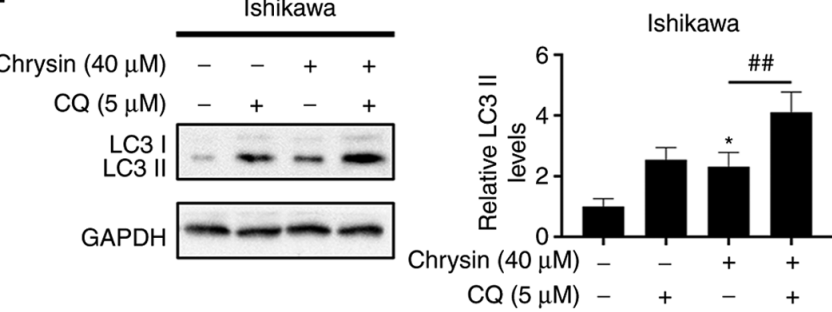

Figure 3. Concentration-dependent effect of chrysin affects the expression of the autophagy-related protein LC3II in endometrial cancer cells (A and B) Following treatment of HEC-1A and Ishikawa cells with various concentrations of chrysin $(0,10,20,40$ and $80 \mu \mathrm{M})$ for $48 \mathrm{~h}$, the levels of LC3II, Beclin 1 and p62 were examined by western blotting. (C and D) HEC-1A and Ishikawa cells were transfected with si-negative control or siATG5 for $24 \mathrm{~h}$, and then treated with chrysin at $40 \mu \mathrm{M}$ for $24 \mathrm{~h}$. The expression of ATG5 and LC3 was detected by western blotting. ${ }^{\#} \mathrm{P}<0.05,{ }^{\# \#} \mathrm{P}<0.01$, ${ }^{\# \# \#} \mathrm{P}<0.001$ vs. siNC (E and F) HEC-1A and Ishikawa cells were untreated or treated with $5 \mu \mathrm{M} \mathrm{CQ}$ for $1 \mathrm{~h}$, followed by chrysin treatment at $40 \mu \mathrm{M}$ for $24 \mathrm{~h}$. The expression levels of LC3II were then examined by western blotting. Values are reported as the mean \pm standard deviation $(\mathrm{n}=3) .{ }^{*} \mathrm{P}<0.05,{ }^{* * *} \mathrm{P}<0.01,{ }^{* * * *} \mathrm{P}<0.001 \mathrm{vs}$. control group; ${ }^{~} \mathrm{P}<0.05,{ }^{\# \#} \mathrm{P}<0.01,{ }^{\# \# "} \mathrm{P}<0.001$ vs. chrysin group. si, small interfering RNA; NC, negative control; ATG5, autophagy-related gene 5; CQ, chloroquinone; LC3, Microtubule-associated proteins 1A/1B light chain 3B.

concentration resulted in the decrease of p-Akt and p-mTOR levels in a concentration-dependent manner (Fig. 6A and B), suggesting that chrysin caused the inactivation of the Akt/mTOR signaling pathway. Pretreatment with LY294002, an inhibitor of PI3K, further decreased p-Akt and p-mTOR expression levels (Fig. 6C and D). Furthermore, LY294002 markedly increased the expression of LC3II induced by chrysin (Fig. 6E and F). These results indicated that the inactivation of the Akt/mTOR signaling pathway by chrysin contributed to autophagy activation in EC cells. 

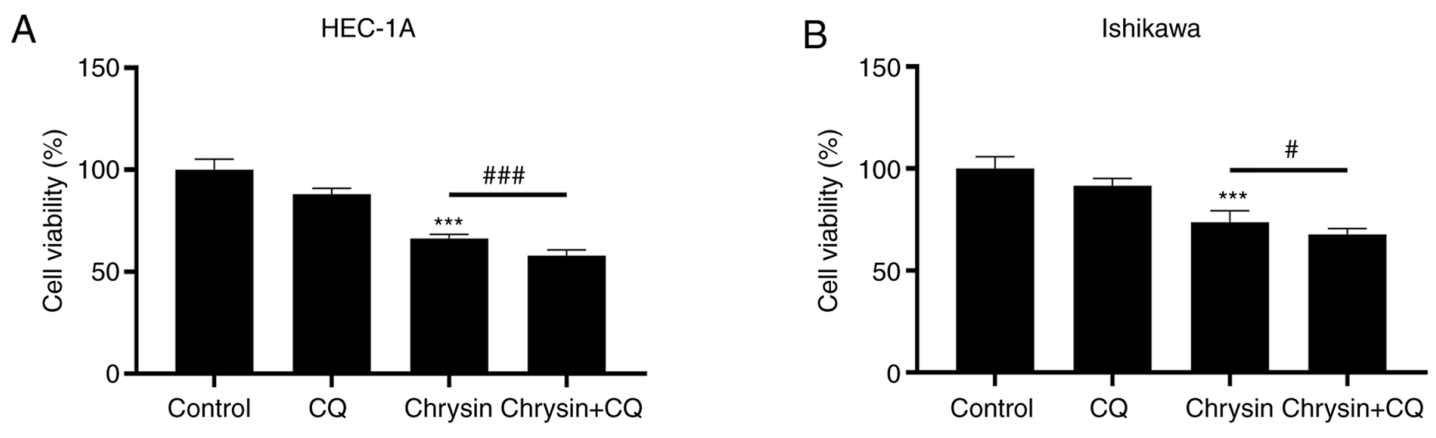

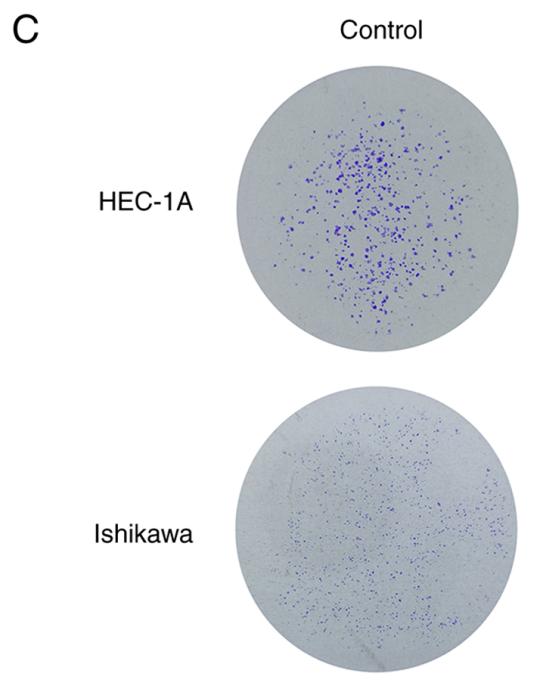

HEC-1A

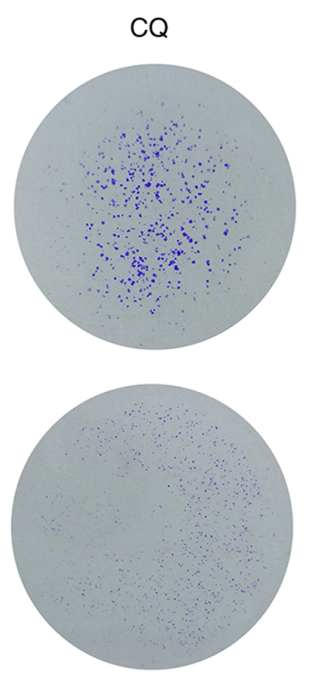

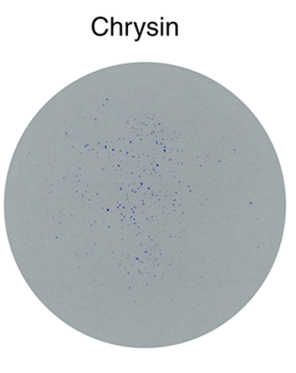

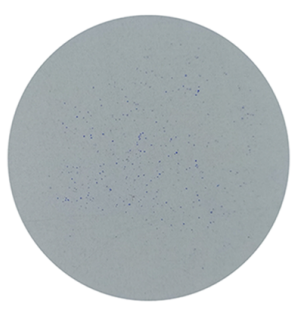

Chrysin $+\mathrm{CQ}$
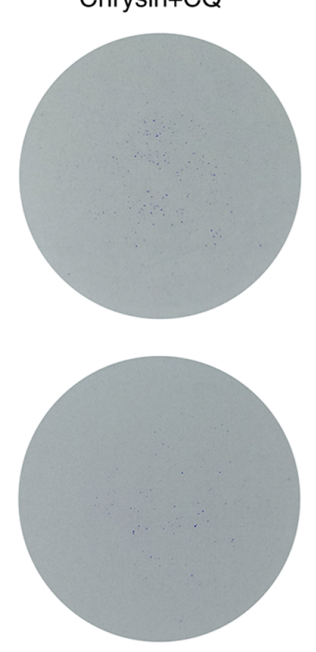

Ishikawa
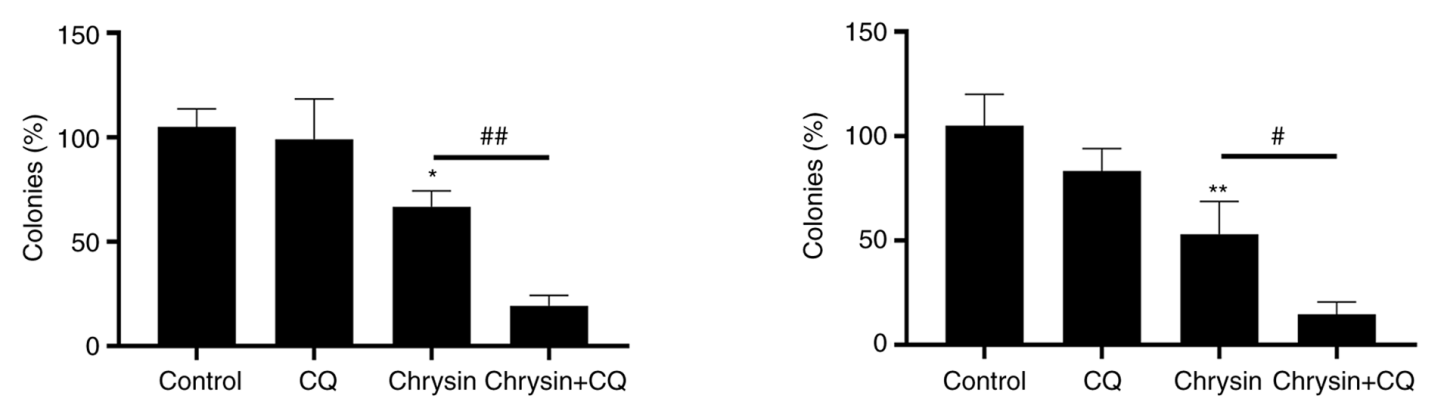

Figure 4. Continued.

Furthermore, HEC-1A and Ishikawa cells were pre-treated with NAC and subsequently treated with chrysin, in order to evaluate the association between Akt/mTOR signal suppression and ROS accumulation. The results of western blotting reveaeld that NAC pretreatment upregulated the expression of p-Akt and p-mTOR in chrysin-treated cells (Fig. 7A and B). Overall, these findings indicated that chrysin inhibited the activity of the Akt/mTOR signaling pathway by inducing the accumulation of intracellular ROS in EC cells.

\section{Discussion}

At present, cisplatin and paclitaxel, which are the first-line chemotherapeutics applied for EC therapy, exert an inhibitory effect on cancer cell growth. However, chemoresistance remains a major obstacle in EC therapy (24). Chrysin has been reported as a potent inhibitor of breast cancer resistance protein, which is one of the ATP-binding cassette (ABC) transporters, and is commonly involved in the multidrug resistance of chemotherapy (25). TNF-related apoptosis-inducing ligand (TRAIL) has been regarded as an anti-cancer agent. However, certain types of cancer, including gliomas, are resistant to TRAIL-induced cell death (26). Chrysin has been shown to overcome TRAIL resistance in breast, pancreatic, cervical, colon, prostate and bladder cancer, as well as in hepatoma and melanoma cells (27). Thus, chrysin represents a potential therapeutic target for the development of clinical applications.

In the present study, it was revealed that chrysin induced protective autophagy through the ROS/Akt/mTOR signaling pathway in EC cells. More specifically, chrysin induced autophagy through the upregulation of the intracellular 

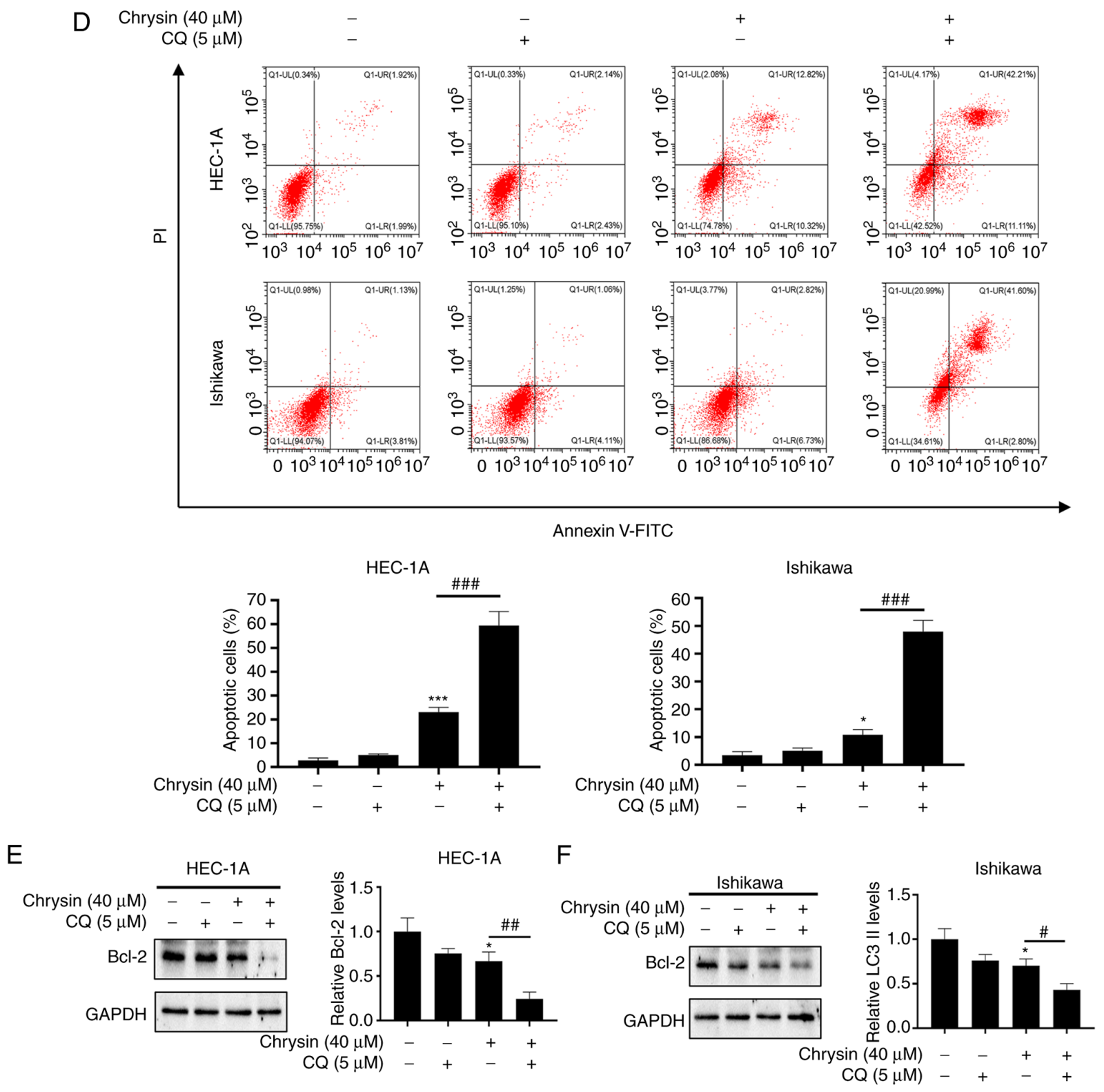

Figure 4. Chrysin induces cytoprotective autophagy in endometrial cancer cells. (A and B) HEC-1A and Ishikawa cells were treated with $40 \mu \mathrm{M}$ chrysin without or with $5 \mu \mathrm{M} \mathrm{CQ}$ for $48 \mathrm{~h}$, and cell viability was then assessed using a CCK-8 assay. (C) HEC-1A and Ishikawa cells were pretreated with CQ $(5 \mu \mathrm{M})$ for $1 \mathrm{~h}$ before being exposed to $40 \mu \mathrm{M}$ chrysin for colony formation assay. (D) HEC-1A and Ishikawa cells were pretreated without or with $5 \mu \mathrm{M} \mathrm{CQ}$ for $1 \mathrm{~h}$, followed by treatment with chrysin $(40 \mu \mathrm{M})$ for $48 \mathrm{~h}$. Cell apoptosis was then analyzed by flow cytometry using Annexin V-FITC/PI staining. (E and F) HEC-1A and Ishikawa cells were untreated or treated with $5 \mu \mathrm{M} \mathrm{CQ}$ for $1 \mathrm{~h}$, followed by chrysin treatment at $40 \mu \mathrm{M}$ for $24 \mathrm{~h}$. Subsequently, the expression levels of Bcl-2 were examined by western blotting. Values are presented as the mean \pm standard deviation $(\mathrm{n}=3) .{ }^{*} \mathrm{P}<0.05,{ }^{* *} \mathrm{P}<0.01,{ }^{* * * *} \mathrm{P}<0.001$ vs. control group; ${ }^{\#} \mathrm{P}<0.05$, ${ }^{\# \#} \mathrm{P}<0.01,{ }^{\# \#} \mathrm{P}<0.001$ vs. chrysin group. CQ, chloroquine; CCK-8, Cell Counting Kit-8; FITC, fluorescein isothiocyanate; PI, propidium iodide.

accumulation of ROS, and the subsequent downregulation of p-Akt and p-mTOR protein levels in EC cells. Suppression of autophagy by CQ potentiated chrysin-induced apoptosis in EC cells.

Targeting autophagy is considered a promising anti-cancer therapy (28). According to previous studies, it has been demonstrated that certain anticancer natural compounds and extracts cab activate autophagy and exert anticancer effects. Dou et al (29) revealed that ivermectin induced autophagy in breast cancer cells, while Yao et al (30) demonstrated that crocin inhibited the growth of hepatocellular carcinoma through activating autophagy. Current attempts to modulate autophagy in a clinical setting are focused on using autophagy inhibition combined with other anti-cancer drugs, which are the focus of $>36$ clinical trials (31). In the present study, it was demonstrated that chrysin induced a protective autophagy response in EC cells. Additionally, the concurrent inhibition of autophagy along with chrysin application suppressed cell proliferation and induced cell apoptosis to a much greater extent than that observed with chrysin treatment alone. The knockdown of ATG5 by siRNA reduced the chrysin-induced accumulation of LC3II in EC cells, demonstrating that chrysin-induced autophagy was ATG5-dependent. The expression level of LC3II, which is closely associated with the number of intracellular autophagosomes, is regarded as an indicator of autophagy (32). CQ, a lysosomal degradation blocker, can improve the $\mathrm{pH}$-value of lysosomes and then destroy the function of lysosomes, inhibit fusion of lysosomes and 
A

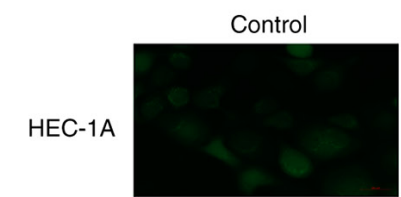

White light

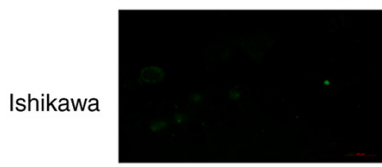

White light

B
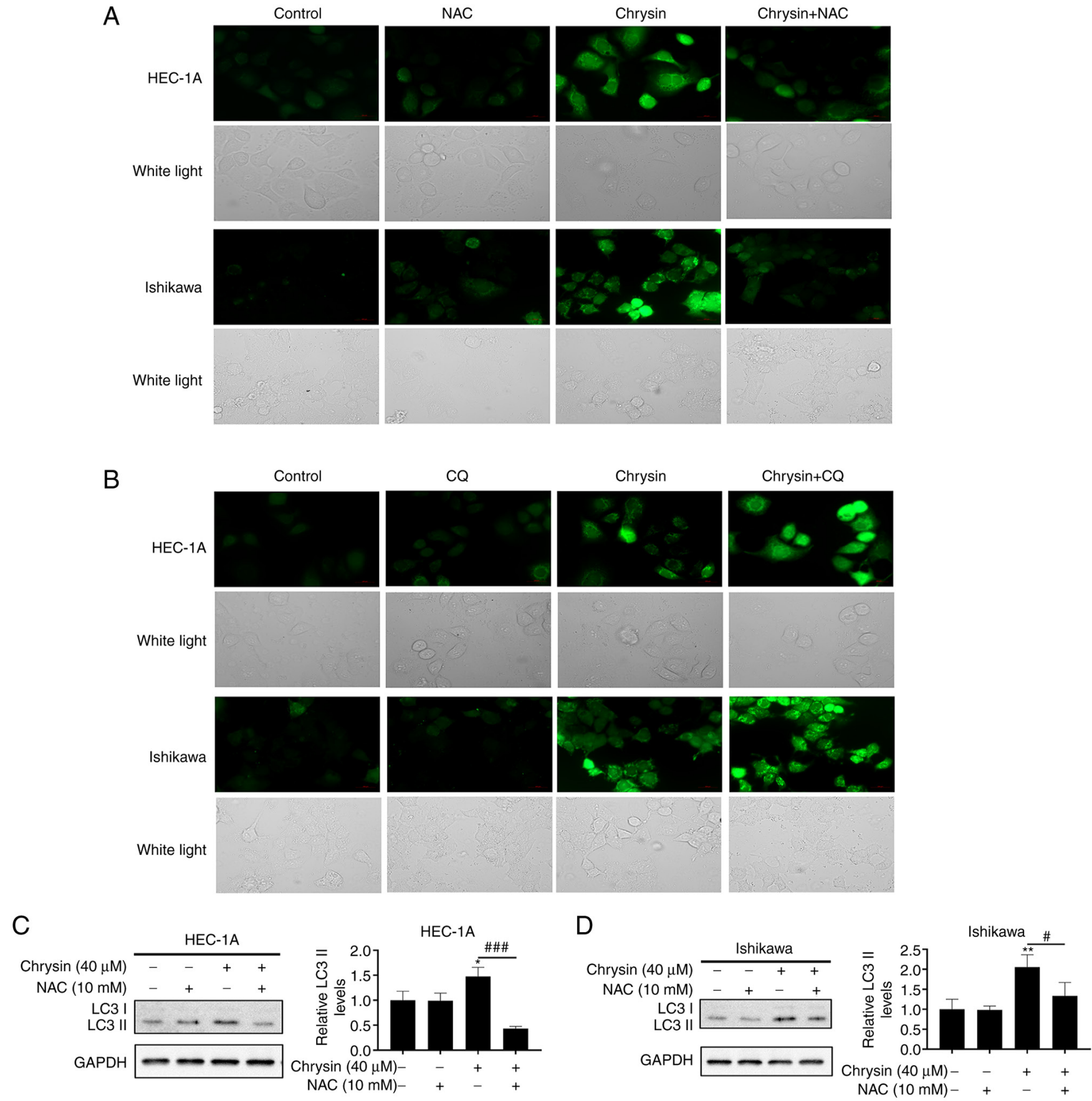

Figure 5. Chrysin induces autophagy via ROS in endometrial cancer cells. (A) Increased levels of intracellular ROS induced by chrysin (40 $\mu \mathrm{M})$ were detected by microscopy. NAC (10 mM) suppressed chrysin-induced ROS increase in HEC-1A and Ishikawa cells. Scale bar, $200 \mu \mathrm{m}$. (B) Increased levels of intracellular ROS induced by chrysin $(40 \mu \mathrm{M})$, as detected by microscopy. CQ $(5 \mu \mathrm{M})$ promoted chrysin-induced ROS accumulation in HEC-1A and Ishikawa cells. Scale bar, $200 \mu \mathrm{m}$. (C and D) HEC-1A and Ishikawa cells were pretreated without or with $10 \mathrm{mM} \mathrm{NAC}$ for $1 \mathrm{~h}$, and then incubated with $40 \mu \mathrm{M}$ chrysin for $24 \mathrm{~h}$. The expression of LC3 was detected by western blotting. ${ }^{*} \mathrm{P}<0.05,{ }^{* *} \mathrm{P}<0.01$ vs. control group; ${ }^{\# \mathrm{P}}<0.05,{ }^{\# \# \#} \mathrm{P}<0.001$ vs. chrysin group. NAC, $\mathrm{N}$-acetylcysteine; ROS, reactive oxygen species; CQ, chloroquinone.

autophagosomes, thus conversely increasing LC3II expression (33). Consequently, it was deduced that the suppression of chrysin-activated autophagy enhanced the anticancer effect of chrysin in EC cells, and may be a robust candidate strategy for EC treatment.

The balance between ROS production and ROS scavenging plays an important in cell homeostasis (34). Notably, ROS may play a dual role in cancer biology, depending on their concentration. At low concentrations, ROS act as signaling molecules involved in promoting cell survival and proliferation, whereas at high concentrations, they induce programmed cell apoptosis and necrosis $(35,36)$. Previously published studies noted that the excessive accumulation of high levels of ROS may trigger cancer cell apoptosis and death and may inhibit cancer progression during enhanced oxidative stress injury (37-39). Thus, it was concluded that, in the process of cancer progression, the analysis of ROS level fluctuation may be of importance for cancer prevention and treatment. Furthermore, autophagy is triggered in response to all types of biological stress, including increased oxidative stress (40). The fluorescence microscopy 
A

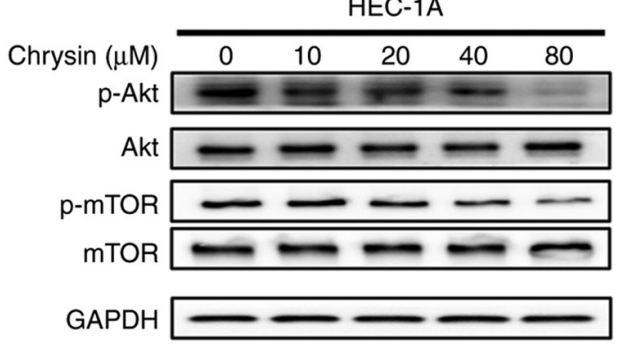

$\mathrm{B}$

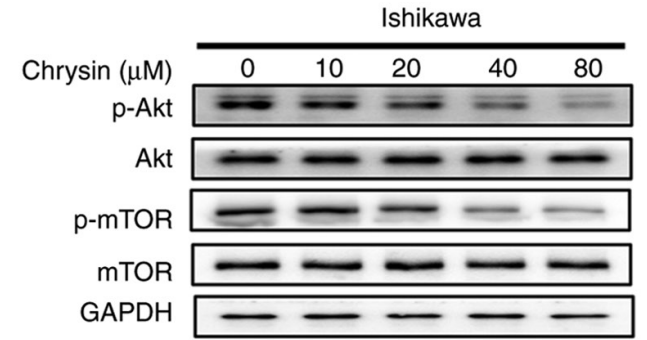

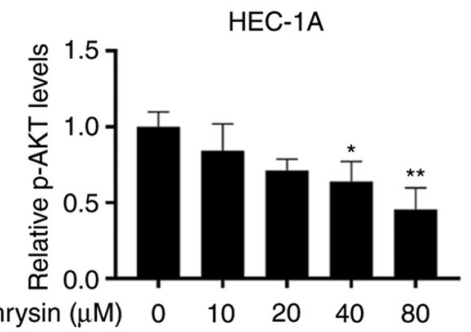

$\begin{array}{llllll}\text { Chrysin }(\mu \mathrm{M}) & 0 & 10 & 20 & 40 & 80\end{array}$

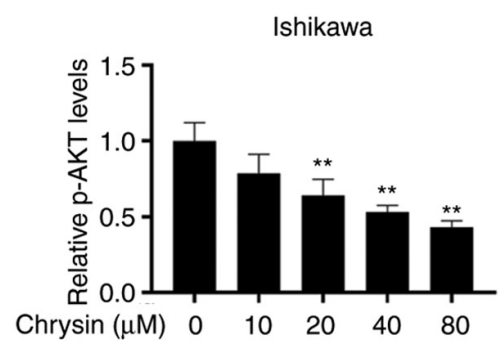

HEC-1A

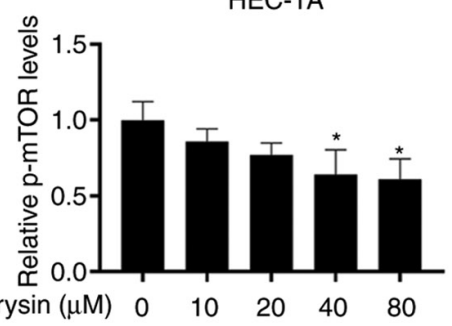

Ishikawa

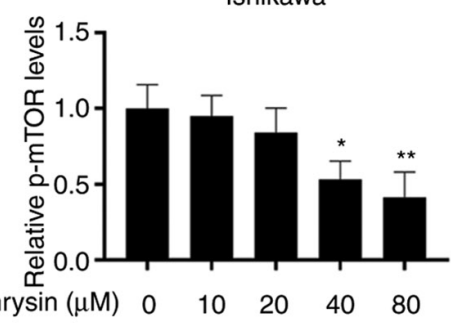

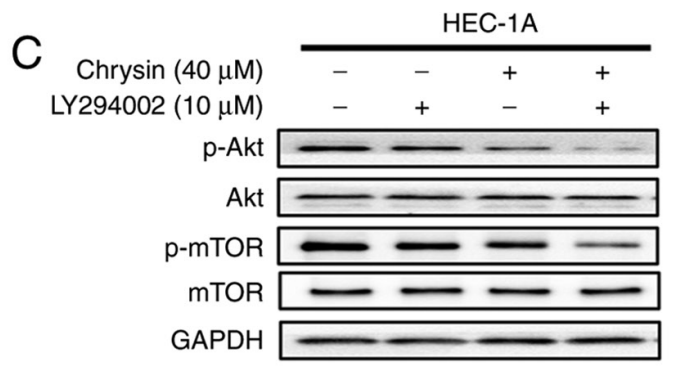
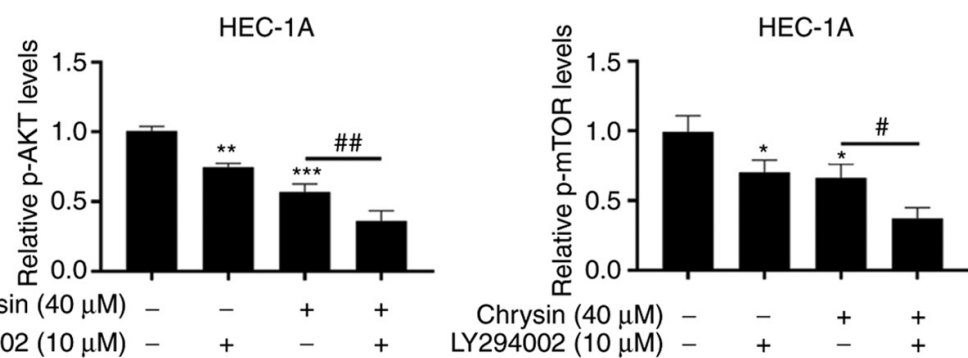

D

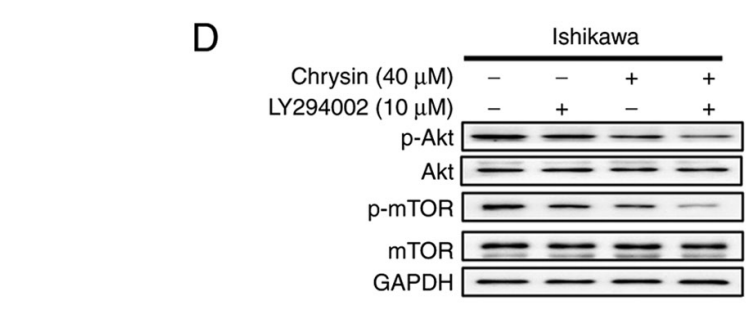

Chrysin $(40 \mu \mathrm{M})$ LY294002 $(10 \mu \mathrm{M})$
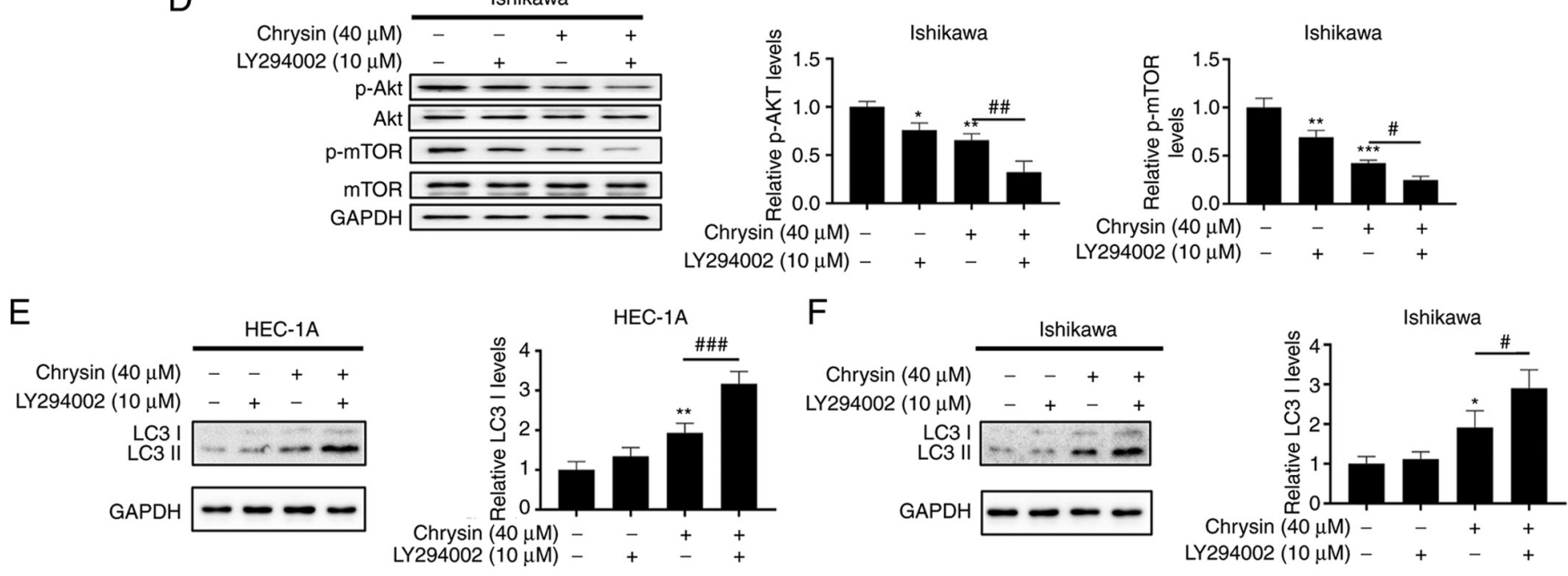

Figure 6. The Akt/mTOR pathway is involved in chrysin-induced autophagy in endometrial cancer cells. (A and B) HEC-1A and Ishikawa cells were exposed to chrysin at different concentrations $(0,10,20,40$ and $80 \mu \mathrm{M})$ for $48 \mathrm{~h}$, and the effects of chrysin on the levels of Akt, p-Akt, mTOR, p-mTOR were examined by western blotting. (C-F) HEC-1A and Ishikawa cells were either not treated, or treated with $10 \mu \mathrm{M} \mathrm{LY} 294002$ for $1 \mathrm{~h}$, and then incubated with $40 \mu \mathrm{M}$ chrysin for $48 \mathrm{~h}$, Next, Akt, p-Akt, mTOR, p-mTOR and LC3II protein expression was analyzed by western blotting. Values are presented as the mean \pm standard deviation of three independent experiments. ${ }^{*} \mathrm{P}<0.05,{ }^{* *} \mathrm{P}<0.01,{ }^{* * * *} \mathrm{P}<0.001$ vs. control group; ${ }^{\#} \mathrm{P}<0.05,{ }^{\# \#} \mathrm{P}<0.01,{ }^{\# \# "} \mathrm{P}<0.001$ vs. chrysin group. $\mathrm{p}-$, phosphorylated.

results of the present study revealed that NAC pretreatment may act as an antioxidant which remarkably inhibits ROS production and the transition from LC3I to LC3II in treated cells, thus suggesting that NAC exhibited a considerable blocking effect on chrysin-induced autophagy. Contrarily, ROS levels were notably higher when chrysin and CQ were applied simultaneously. Therefore, it was hypothesized that chrysin-induced autophagy played a protective role; however, when oxidative stress reached a degree beyond the control of the protective response of autophagy, cell death may occur by apoptosis in EC cells. These results were also consistent with the results of the aforementioned apoptotic studies. Collectively, these results implied that chrysin-induced ROS accumulation may act as an autophagy inducer in EC cells (Fig. 8).

The Akt/mTOR signaling pathway is frequently activated in human tumors and is one of the main growth regulatory 
A

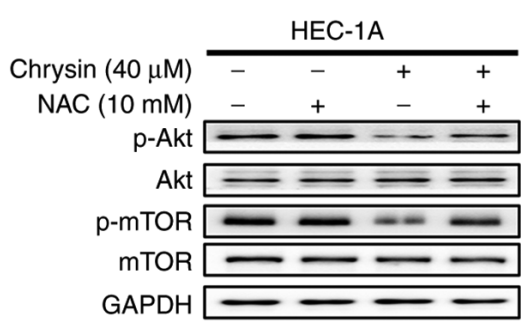

B

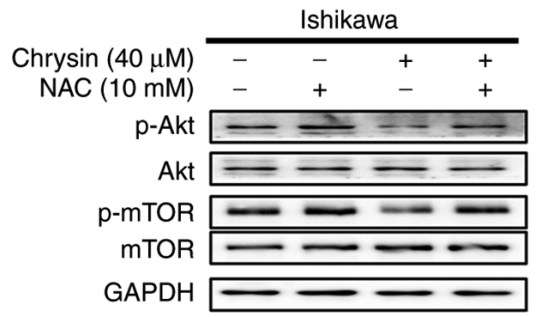

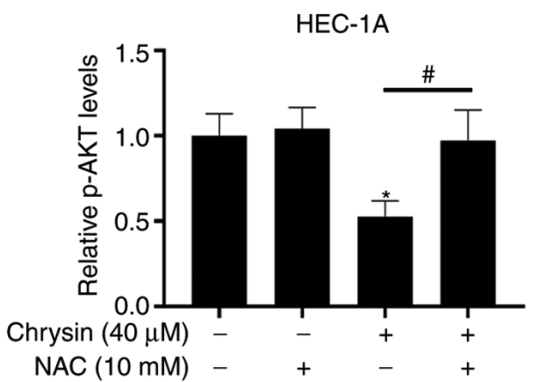

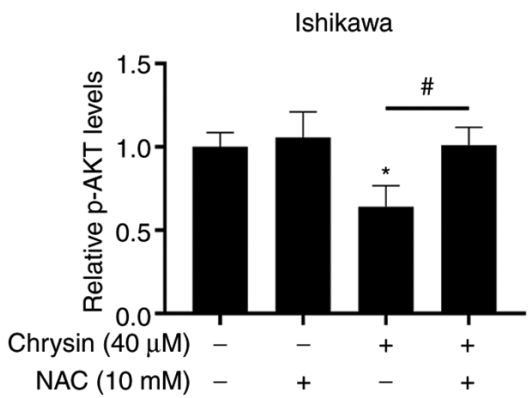

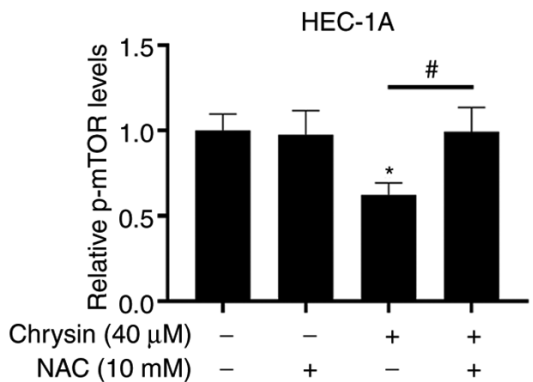

Ishikawa

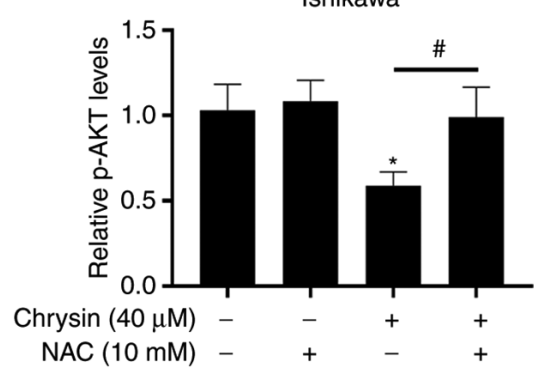

Figure 7. ROS-mediated inactivation of the Akt/mTOR signaling pathway is involved in autophagy induced by chrysin in endometrial cancer cells. (A and B) HEC-1A and Ishikawa cells were pretreated without or with $10 \mathrm{mM} \mathrm{NAC} \mathrm{for} 1 \mathrm{~h}$, and then incubated with $40 \mu \mathrm{M}$ chrysin for $48 \mathrm{~h}$. Next, Akt, p-Akt, mTOR and p-mTOR protein expression was analyzed by western blotting. The results are presented as the mean \pm standard deviation of three independent tests. ${ }^{*} \mathrm{P}<0.05$ vs. control group; ${ }^{*} \mathrm{P}<0.05$ vs. chrysin group. p-, phosphorylated; ROS, reactive oxygen species; NAC, $N$-acetylcysteine.
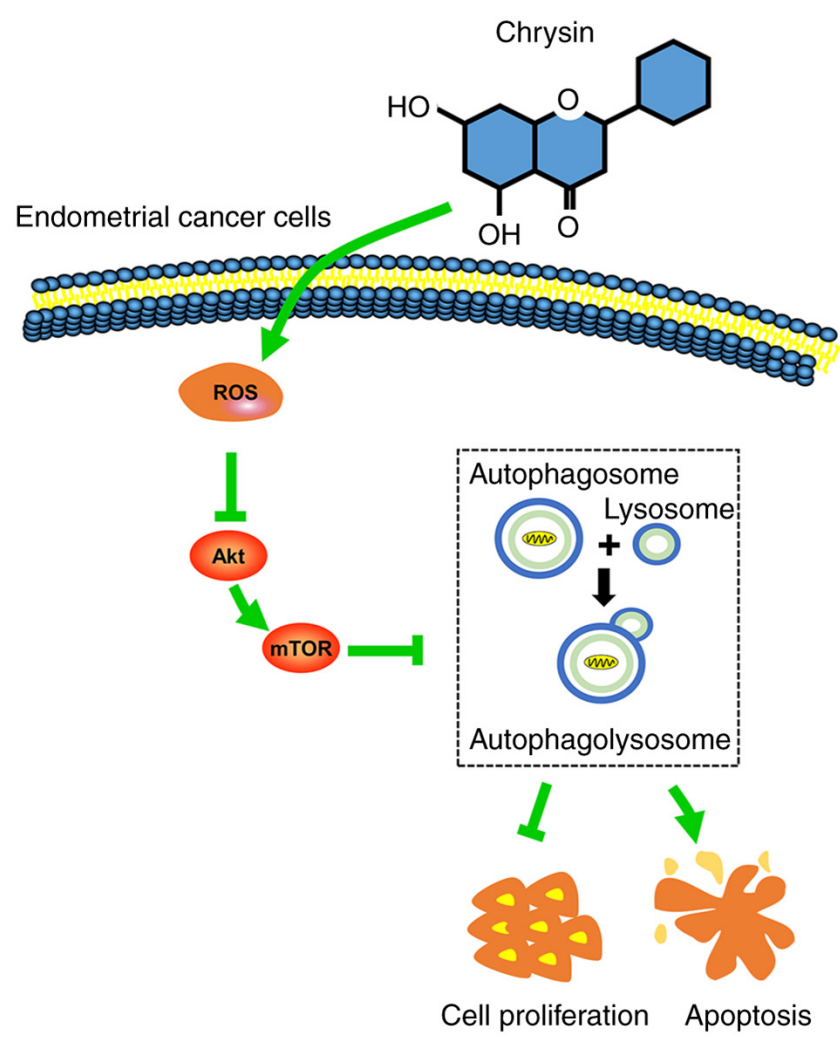

Figure 8. Mechanism of chrysin-induced autophagy in endometrial cancer cells.

pathways (41). Akt is a key upstream regulator of mTOR, and Akt activation may lead to the phosphorylation of the downstream effector mTOR, thereby negatively regulating autophagy $(42,43)$. In the present study, chrysin suppressed Akt/mTOR signaling, indicating that chrysin induced autophagy by targeting Akt/mTOR signaling. In previously published studies, it was indicated that cellular oxidative stress is associated with the Akt/mTOR signaling pathway, and Akt and mTOR are two kinases regulated by ROS $(44,45)$. The present study revealed that NAC reversed the decrease of p-Akt and p-mTOR in chrysin-treated cells, which demonstrated the association between Akt/mTOR signal suppression and ROS accumulation by chrysin. Chrysin inhibited the growth of cancer cells by increasing oxidative stress and subsequently inhibiting the Akt/mTOR signaling pathway. Overall, the results suggested that chrysin-induced autophagy was triggered by inactivation of the ROS-mediated Akt/mTOR signaling pathway.

However, there were certain limitations to the present study. Firstly, only in vitro experiments were conducted. Therefore, animal experiments should be carried out to confirm the effectiveness of chrysin in vivo. Furthermore, our findings were limited to EC and did not verify the effect of chrysin in tumors other than EC, which should be investigated in future studies. Subsequently, the present study demonstrated that chrysin inhibited cell proliferation by CCK-8 and colony formation assay. It is preferable to detect the expression of cell cycle-related proteins including cyclins or CDKs in order to strengthen these conclusions. And finally, it is well known that ROS are produced from peroxisomes, the endoplasmic reticulum, and mitochondria, which is their primary source (46). Regrettably, the present study did not detect the production of ROS in mitochondria.

In conclusion, the present study confirmed for the first time, at least to the best of our knowledge, that the ROS-mediated Akt/mTOR signaling pathway played a key role in chrysin-induced autophagy in EC cells. Chrysin also induced the apoptosis of EC cells. It was also demonstrated that the inhibition of autophagy by CQ enhanced the chrysin-induced 
inhibition of cell proliferation and promoted chrysin-induced apoptosis, indicating that chrysin-induced autophagy played a pro-survival role in EC cells. Thus, combination treatment with an autophagy inhibitor may be a promising intervention strategy for EC treatment.

\section{Acknowledgements}

Not applicable.

\section{Funding}

This study was funded by the National Science Foundation for Young Scientists of China (grant. no. 81801511).

\section{Availability of data and materials}

The datasets used and/or analyzed during the current study are available from the corresponding author on reasonable request.

\section{Authors' contributions}

The present study was conceived and designed by YH, YY, LZ and BW. The experiments were conducted by YH, YS, YY, HH, YF and YW. YH and YS wrote the manuscript with support from BW and YY, HH, YF, YW LZ and BW critically revised the manuscript for important intellectual content. All authors agreed to be accountable for all aspects of the work in ensuring that questions related to the accuracy or integrity of any part of the work are appropriately investigated and resolved. YH and BW confirm the authenticity of all the raw data. All authors have read and approved the final manuscript.

\section{Ethics approval and consent to participate}

Not applicable.

\section{Patient consent for publication}

Not applicable.

\section{Competing interests}

The authors declare that they have no competing interests.

\section{References}

1. Urick ME and Bell DW: Clinical actionability of molecular targets in endometrial cancer. Nat Rev Cancer 19: 510-521, 2019.

2. Troisi J, Raffone A, Travaglino A, Belli G, Belli C, Anand S, Giugliano L, Cavallo P, Scala G, Symes S, et al: Development and validation of a serum metabolomic signature for endometrial cancer screening in postmenopausal women. JAMA Netw Open 3: e2018327, 2020.

3. Clarke MA, Long BJ, Del Mar Morillo A, Arbyn M, Bakkum-Gamez JN and Wentzensen N: Association of endometrial cancer risk with postmenopausal bleeding in women: A systematic review and meta-analysis. JAMA Intern Med 178: 1210-1222, 2018.

4. Korets SB, Czok S, Blank SV, Curtin JP and Schneider RJ: Targeting the mTOR/4E-BP pathway in endometrial cancer. Clin Cancer Res 17: 7518-7528, 2011.
5. Rai R, Essel KG, Benbrook DM, Garland J, Zhao YD and Chandra V: Preclinical efficacy and involvement of AKT, mTOR, and ERK kinases in the mechanism of sulforaphane against endometrial cancer. Cancers (Basel) 12: 1273, 2020.

6. Ma L, Zhang M, Zhao R, Wang D, Ma Y and Li A: Plant natural products: Promising resources for cancer chemoprevention. Molecules 26: 933, 2021.

7. Sauter ER: Cancer prevention and treatment using combination therapy with natural compounds. Expert Rev Clin Pharmacol 13: 265-285, 2020

8. Song S, Gao K, Niu R, Wang J, Zhang J, Gao C, Yang B and Liao X: Inclusion complexes between chrysin and amino-appended $\beta$-cyclodextrins (ACDs): Binding behavior, water solubility, in vitro antioxidant activity and cytotoxicity. Mater Sci Eng C Mater Biol Appl 106: 110161, 2020.

9. Mani R and Natesan V: Chrysin: Sources, beneficial pharmacological activities, and molecular mechanism of action. Phytochemistry 145: 187-196, 2018.

10. Kasala ER, Bodduluru LN, Madana RM, Athira KV, Gogoi R and Barua CC: Chemopreventive and therapeutic potential of chrysin in cancer: Mechanistic perspectives. Toxicol Lett 233: 214-225, 2015.

11. Moghadam ER, Ang HL, Asnaf SE, Zabolian A, Saleki H, Yavari M, Esmaeili H,Zarrabi A, Ashrafizadeh M and Kumar AP: Broad-spectrum preclinical antitumor activity of chrysin: Current trends and future perspectives. Biomolecules 10: 1374, 2020.

12. Roy S, Sil A and Chakraborty T: Potentiating apoptosis and modulation of $\mathrm{p} 53, \mathrm{Bcl} 2$, and $\mathrm{Bax}$ by a novel chrysin ruthenium complex for effective chemotherapeutic efficacy against breast cancer. J Cell Physiol 234: 4888-4909, 2019.

13. Brechbuhl HM, Kachadourian R, Min E, Chan D and Day BJ: Chrysin enhances doxorubicin-induced cytotoxicity in human lung epithelial cancer cell lines: The role of glutathione. Toxicol Appl Pharmacol 258: 1-9, 2012.

14. Zhang T, Chen X, Qu L, Wu J, Cui R and Zhao Y: Chrysin and its phosphate ester inhibit cell proliferation and induce apoptosis in hela cells. Bioorg Med Chem 12: 6097-6105, 2004.

15. Lima APB, Almeida TC, Barros TMB, Rocha LCM, Garcia CCM and da Silva GN: Toxicogenetic and antiproliferative effects of chrysin in urinary bladder cancer cells. Mutagenesis 13: geaa021, 2020.

16. Koff JL, Ramachandiran S and Bernal-Mizrachi L: A time to kill: Targeting apoptosis in cancer. Int J Mol Sci 16: 2942-2955, 2015.

17. Pang X, Zhang X, Jiang Y, Su Q, Li Q and Li Z: Autophagy: Mechanisms and therapeutic potential of flavonoids in cancer. Biomolecules 11: 135, 2021.

18. Crawley O, Opperman KJ, Desbois M, Adrados I, Borgen MA, Giles AC, Duckett DR and Grill B: Autophagy is inhibited by ubiquitin ligase activity in the nervous system. Nat Commun 10: 5017, 2019.

19. Ranieri R, Ciaglia E, Amodio G, Picardi P, Proto MC, Gazzerro P, Laezza C, Remondelli P, Bifulco M and Pisanti S: N6-isopentenyladenosine dual targeting of AMPK and rab7 prenylation inhibits melanoma growth through the impairment of autophagic flux. Cell Death Differ 25: 353-367, 2018.

20. Lin YM, Chen CI, Hsiang YP, Hsu YC, Cheng KC, Chien PH, Pan HL, Lu CC and Chen YJ: Chrysin attenuates cell viability of human colorectal cancer cells through autophagy induction unlike 5-fluorouracil/oxaliplatin. Int J Mol Sci 19: 1763, 2018.

21. Garcia-Martinez T, Vendrell-Flotats M, Martinez-Rodero I, Ordóñez-León EA, Álvarez-Rodríguez M, López-Béjar M, Yeste $\mathrm{M}$ and Mogas T: Glutathione ethyl ester protects in vitro-maturing bovine oocytes against oxidative stress induced by subsequent vitrification/warming. Int J Mol Sci 21: 7547, 2020.

22. An Z, Tassa A, Thomas C, Zhong R, Xiao G, Fotedar R, Tu BP, Klionsky DJ and Levine B: Autophagy is required for G1/G0 quiescence in response to nitrogen starvation in Saccharomyces cerevisiae. Autophagy 10: 1702-1711, 2014.

23. Nunez-Olvera SI, Gallardo-Rincon D, Puente-Rivera J, Salinas-Vera YM, Marchat LA, Morales-Villegas R and López-Camarillo C: Autophagy machinery as a promising therapeutic target in endometrial cancer. Front Oncol 9: 1326, 2019.

24. Guo F, Zhang H, Jia Z, Cui M and Tian J: Chemoresistance and targeting of growth factors/cytokines signalling pathways: Towards the development of effective therapeutic strategy for endometrial cancer. Am J Cancer Res 8: 1317-1331, 2018.

25. Sharom FJ: ABC multidrug transporters: Structure, function and role in chemoresistance. Pharmacogenomics 9: 105-127, 2008. 
26. Crommentuijn MH, Maguire CA, Niers JM, Vandertop WP Badr CE, Würdinger $T$ and Tannous BA: Intracranial AAV-sTRAIL combined with lanatoside $\mathrm{C}$ prolongs survival in an orthotopic xenograft mouse model of invasive glioblastoma. Mol Oncol 10: 625-634, 2016.

27. Bronikowska J, Szliszka E, Kostrzewa-Susłow E, Jaworska D, Czuba ZP, Bednarski P and Król W: Novel structurally related flavones augment cell death induced by rhsTRAIL. Int J Mol Sci 18: 1211, 2017

28. Rybstein MD, Bravo-San Pedro JM, Kroemer G and Galluzzi L: The autophagic network and cancer. Nat Cell Biol 20: 243-251, 2018.

29. Dou QH, Chen HN, Wang K, Yuan K, Lei Y, Li K, Lan J, Chen Y, Huang Z, Xie N, et al: Ivermectin induces cytostatic autophagy by blocking the PAK1/akt axis in breast cancer. Cancer Res 76: 4457-4469, 2016.

30. Yao C, Liu BB, Qian XD, Li LQ, Cao HB, Guo QS and Zhou GF: Crocin induces autophagic apoptosis in hepatocellular carcinoma by inhibiting Akt/mTOR activity. Onco Targets Ther 11: 2017-2028, 2018

31. Amaravadi RK, Lippincott-Schwartz J, Yin XM, Weiss WA Takebe N, Timmer W, DiPaola RS, Lotze MT and White E: Principles and current strategies for targeting autophagy for cancer treatment. Clin Cancer Res 17: 654-666, 2011.

32. Ohnishi K, Yano S, Fujimoto M, Sakai M, Harumoto E, Furuichi A, Masuda M, Ohminami H, Yamanaka-Okumura H, Hara T and Taketani Y: Identification of dietary phytochemicals capable of enhancing the autophagy flux in HeLa and Caco-2 human cell lines. Antioxidants (Basel) 9: 1193, 2020.

33. Lu Y, Xiao L, Liu Y, Wang H, Li H, Zhou Q, Pan J, Lei B, Huang A and Qi S: MIR517C inhibits autophagy and the epithelial-to-mesenchymal (-like) transition phenotype in human glioblastoma through KPNA2-dependent disruption of TP53 nuclear translocation. Autophagy 11: 2213-2232, 2016

34. Kim K, Dayem AA, Gil M, Yang GM, Lee SB, Kwon OH, Choi S, Kang GH, Lim KM, Kim D and Cho SG: 3,2'-Dihydroxyflavone improves the proliferation and survival of human pluripotent stem cells and their differentiation into hematopoietic progenitor cells. J Clin Med 9: 669, 2020

35. Lewinska A, Adamczyk-Grochala J, Deregowska A and Wnuk M: Sulforaphane-induced cell cycle arrest and senescence are accompanied by DNA hypomethylation and changes in microRNA profile in breast cancer cells. Theranostics 7 3461-3477, 2017.

36. Ye S, Zhao T, Zhang W, Tang Z, Gao C, Ma Z, Xiong JW, Peng J, Tan WQ and Chen J: p53 isoform $\Delta 113$ p53 promotes zebrafish heart regeneration by maintaining redox homeostasis. Cell Death Dis 11: 568,2020 .
37. Deng L, Gao X, Liu B, He X, Xu J, Qiang J, Wu Q and Liu S: NMT1 inhibition modulates breast cancer progression through stress-triggered JNK pathway. Cell Death Dis 9: 1143, 2018.

38. Yang CC, Tsai MH, Li KY, Hou CH and Lin FH: Carbon-doped $\mathrm{TiO}_{2}$ activated by $\mathrm{X}$-ray irradiation for the generation of reactive oxygen species to enhance photodynamic therapy in tumor treatment. Int J Mol Sci 20: 2072, 2019.

39. Lim W, Ryu S, Bazer FW, Kim SM and Song G: Chrysin attenuates progression of ovarian cancer cells by regulating signaling cascades and mitochondrial dysfunction. J Cell Physiol 233: 3129-3140, 2018.

40. Ru JY and Wang YF: Osteocyte apoptosis: The roles and key molecular mechanisms in resorption-related bone diseases. Cell Death Dis 11: 846, 2020.

41. Guglielmelli P, Barosi G, Rambaldi A, Marchioli R, Masciulli A, Tozzi L, Biamonte F, Bartalucci N, Gattoni E, Lupo ML, et al: Safety and efficacy of everolimus, a mTOR inhibitor, as single agent in a phase $1 / 2$ study in patients with myelofibrosis. Blood 118: 2069-2076, 2011.

42. Zhou Y, Chen X, Qu N, Zhang B and Xia C: Chondroprotection of PPAR $\alpha$ activation by WY14643 via autophagy involving akt and ERK in LPS-treated mouse chondrocytes and osteoarthritis model. J Cell Mol Med 23: 2782-2793, 2019.

43. Wang YX, Yang L, Wang HQ, Zhao XQ, Liu T, Li YH, Zeng QX, Li YH and Song DQ: Synthesis and evolution of berberine derivatives as a new class of antiviral agents against enterovirus 71 through the MEK/ERK pathway and autophagy. Molecules 23: 2084, 2018

44. Ives A, Nomura J, Martinon F, Roger T, LeRoy D, Miner JN, Simon G, Busso N and So A: Xanthine oxidoreductase regulates macrophage IL1 $\beta$ secretion upon NLRP3 inflammasome activation. Nat Commun 6: 6555, 2015.

45. Su Z, Burchfield JG, Yang P, Humphrey SJ, Yang G, Francis D, Yasmin S, Shin SY, Norris DM, Kearney AL, et al: Global redox proteome and phosphoproteome analysis reveals redox switch in akt. Nat Commun 10: 5486, 2019.

46. Huang CR, Chang TW, Lee CT, Shen CJ, Chang WC and Chen BK: ARNT deficiency represses pyruvate dehydrogenase kinase 1 to trigger ROS production and melanoma metastasis. Oncogenesis 10: 11, 2021. 